\title{
How Ethical Leadership Encourages Employee Voice Behavior in China: The Mediating Role of Organizational Harmony
}

\author{
Tachia Chin ${ }^{1}$ \\ ${ }^{1}$ School of English for International Business, Guangdong University of Foreign Studies, China \\ Corresponding: Tachia Chin, School of English for International Business, Guangdong University of Foreign \\ Studies, Guangzhou, P. R. China. E-mail: tachia1231@yahoo.com.sg
}

Received: July 1, 2013

Accepted: July 23, 2013

Online Published: September 23, 2013

doi:10.5539/ibr.v6n10p15

URL: http://dx.doi.org/10.5539/ibr.v6n10p15

\begin{abstract}
This paper examines that ethical leadership encourages employees to engage in voice behavior via increasing organizational harmony in China. Using quantitative methods, the results suggest that ethical leadership is positively related to employee-perceived harmony and employee voice. Moreover, ethical leadership is proved to significantly enhance voice behavior through promoting organizational harmony in the Chinese workplace. This research therefore contributes to the leadership literature, seeing that it develops a context-specific framework linking the unique Chinese cultural idiosyncrasy "harmony" to the relationship between ethical leadership and employee voice. In terms of practical implications, the findings enable foreign entrepreneurs to gain a better understanding of the role and the conduct of ethical leadership in the Chinese context.
\end{abstract}

Keywords: ethical leadership, voice, culture, harmony, China

\section{Introduction}

Recessions, uncertainties and growing risks in global environments today highlight the importance of ethical issues in organizations (Wang \& Snell, 2012; Hannah, Avolio, \& May, 2011; Ardichvili \& Jondle, 2009; Walumbwa \& Schaubroeck, 2009; Zhu, 2008). Following the collapse of global financial system, the world business is continuously hit by fraud, deceit and greed, which have resulted in far more severe corporate debt and credit crisis. In China, the world's second-largest economy, dozens of bosses of small and medium sized enterprises (SMEs) in Wenzhou encountering a liquidity crunch in 2011 have committed suicide or gone into hiding after borrowing heavily from loan sharks. The escalating scope and scale of malfeasance in business are imposing critical moral challenges on organization leaders nowadays. Therefore, despite more difficulties in developing ethical values within an organization in such turbulent times, never did we expect more of ethical leadership.

Ethical leadership is of great importance to handling moral incidents and fostering employees' ethical behaviors in organizations given that good leaders are obliged to set a moral example for their followers (Hannah et al., 2011; Ardichvili \& Jondle, 2009; Brown, Trevino, \& Harrison, 2005). There have been studies examining that ethical leadership is significantly associated to employees' prosocial behavior, counterproductive behavior, job satisfaction, and organizational commitment (e.g., Zhu, 2008; Brown \& Trevino, 2006). However, the extant literature still shows some limitations. For instance, it is vital for researchers to incorporate the cultural context into their predictions of leadership effectiveness and development while all leadership interactions may differ in distinct sociocultural environments (Avolio \& Gardner, 2005). Hence, notwithstanding the great impacts of ethical leadership on organizational culture and employee outcomes have been confirmed (Ardichvili, Jondle, Kowske, Cornachione, \& Thakadipuram, 2011; Schminke, Arnaud, \& Kuenzi, 2007), the mediating mechanism of a specific cultural context on the relationships between leaders' morality and followers' attitudes and behaviors need further investigation, remaining one of the most under-researched topics.

One prominent characteristic for Chinese to deal with leader-follower problems is the particular emphasis on the value of harmony that encourages organizational members to avoid interpersonal disagreement and transgression, and build good relationships with each other (Chin, 2013; Leung, Brew, Zhang, \& Zhang, 2011; Han \& Altman, 2010; Hofstede, Hofstede, \& Minkov, 2010; Chen \& Miller, 2010; Tjosvold, Wu, \& Chen, 2010). The Chinese notion of harmony, with the tendency to focus more on interpersonal harmony in organizations, is at the earliest originated from the Confucian canon I Ching, reflecting the ideal of all human relationships as well as the basic 
logic of people's perception of social governance and ordering in the Chinese context (Chen \& Miller, 2011; Luo \& Rui, 2010; Lai, 2008). Hence, it is plausible to use harmony as the critical contextual variable for this research.

Employees' voice, as a kind of employees' expression of challenging but constructive opinions, concerns or ideas about work-related issues, is believed to be associated with a variety of positive organizational outcomes such as innovation, improvement of work processes, and crisis prevention (Liang, Farh, \& Farh, 2012). Moreover, voice behaviors can be engendered in subordinates by ethical leadership (Walumbwa \& Schaubroeck, 2009). Hence, employee voice behavior is suitable to be used as a positive outcome variable here.

To fill the above-mentioned research gap, this paper, in considering the foregoing arguments, aims to investigate the following question: Could ethical leadership encourage employee voice behavior via the mediating mechanism of harmony in Chinese organizations?

This study yields three contributions. First, despite the burgeoning studies on ethical leadership, this research contributes to the literature by developing an instructive theoretical framework linking the unique cultural characteristic harmony in China to the conduct of ethical leadership. Second, this research responds to a recent appeal from numerous organizations and governments for more focus on ethics development at workplace in the face of more difficult and complex moral challenges nowadays. Third, while China has maintained its position as the most attractive destination of foreign direct investment every year since 2002 (Global Business Policy Council, 2010), this paper especially helps expatriate managers to gain a better understanding of the role of ethical leadership in human resource management (HRM) in the Chinese context.

\section{Theoretical Foundations and Hypotheses}

\subsection{Ethical Leadership}

The theories of ethical leadership have been discussed by numerous scholars in the field of leadership, organizational behavior and management (Mayer, Aquino, Greenbaum, \& Kuenzi, 2012; Hannah et al., 2011; Chen, 2010; Zhu, 2008; Brown \& Trevino, 2006; Avolio \& Gardner, 2005; Brown et al., 2005). The recent high profile accounting frauds and misreporting by CEOs involving major companies worldwide such as Worldcom, Enron and Satyam have further raised greater ethical concerns about the CEO's integrity and morality. It is believed that one critical cause resulting in these failures lies in their CEOs' unethical behaviors. Hence, management scholars have continuously put emphasis on examining the role of ethical leadership and its related mechanisms in organizations.

Growing studies recognize Brown et al.'s (2005) definition of “ethical leadership" from a social learning perspective (Bandura, 1986) as "the demonstration of normatively appropriate conduct through personal actions and interpersonal relationships, and the promotion of such conduct to followers through two-way communication, reinforcement, and decision-making". This conceptualization highlights that there are three key building blocks of ethical leadership: treating people fairly, acting as a moral role model that allows followers to learn appropriate ethical behaviors from their leader, and actively managing morality. More specifically, it sheds light on the transformational mode of ethical leadership associated with role modeling and inspirational motivation by leaders (e.g., Ardichvili \& Jondle, 2009; Kirkman, Chen, Farh, Chen, \& Lowe, 2009; Avolio \& Gardner, 2005), as well as the transactional mode regarding control strategies by which leaders can ensure the employees' engagement in ethical behaviors (Brown \& Trevino, 2006). In this vein, an ethical leader, as a moral exemplar, encourages subordinates to display moral behaviors not only by coaching and guidance but by rewards and sanctions that can elicit the followers' compliance to do so (Mayer et al., 2012; Brown \& Trevino, 2006). To sum up, it is believed that ethical leaders are seen as principled decision makers of great virtues such as integrity, determination, fairness, honesty, humility, tolerance, enthusiasm, courage and responsibility that are worthy of emulation by followers (Mayer et al., 2012; Walumbwa \& Schaubroeck, 2009).

Butcher (1997) suggests that "ethical business leadership requires not only investing in the small trees and experimental hybrids that won't yield a thing that in this quarter or next, but also caring for the soil that allows us to produce such a harvest in the first place". In light of this argument, an ethical leader should be responsible for creating the right condition, namely, the suitable organizational soil or culture/climate to nourish the moral development of followers in an organization. In other word, ethical leadership appears to be a key determinant for constituting ethical business culture in enterprises. According to Ardichvili, Mitchell, and Jondle (2009), the concept of ethical corporate culture can be described as a type of organizational culture based on "an alignment between formal structures, processes and policies, consistent ethical behavior of top leadership, and informal recognition of heroes, stories, rituals, and language that inspire organizational members to behave in a manner accorded with high ethical standards that have been set by executive leadership". Indeed, compelling evidence 
has revealed a direct and significant link between the moral characters of corporate leaders and the quality of ethical business climate/cultures within organizations (Ardichvili \& Joudle, 2009; Schminke et al., 2007). Hence, it is recognized that a top leader's moral behaviors and ethics play a critically important role in shaping and developing ethical organizational culture (Ardichvili et al., 2011).

Reviews of cross-cultural literature indicate that organizational culture could not ease or at least does not diminish the influence of national culture upon leaders' and employees' attitudes and behaviors (Ardichvili et al., 2011). It is because that national cultures signify the fundamental variances in human 'collective mental programming' (Hofstede et al., 2010), namely, the distinctive cultural traits rooted in people's mind. Viewed from this angle, the salient cultural trait of a nation should be embodied and embedded in corporate culture in this nation's specific context. As far as China is concerned, literature suggests that the pursuit of harmony, as the ideal in Confucian thought symbolizing the all-embracing characteristic of Chinese culture, pinpoints the desired means as well as the ultimate goal/end in terms of establishing all kinds of relationships, particularly the interpersonal relationships in the Chinese contexts (Chen \& Miller, 2011; Han \& Altman, 2010; Tjosvold et al., 2010; Chin, 2010; 2012; Luo \& Rui, 2009; Cheng, 2006). Hence, it is reasonable to posit that the unique Chinese propensity to maintain interpersonal harmony is deeply rooted in organizational culture in Chinese organizations.

As mentioned at the outset, the Chinese notion of harmony is originally derived from the most influential and ancient philosophical scripture I Ching, which was written more than 3,000 years ago. I Ching is widely recognized as the pivotal scripture of many early Chinese philosophical thoughts, particularly Confucianism and Daoism. The theme of harmony lying at the heart of I Ching can be comprehensively analyzed and demonstrated by the basic eight-trigram model. Following this logic, Chin (2010) conducted an empirical study to examine if the employee-perceived harmony at workplace reflects the connotation and denotation of the eight-trigram model in China. This research showed an eight-factor construct that fit the eight-trigram model very well, demonstrating how Chinese employees define the ideal status of organizational harmony at workplace, including harmony of individual worker with himself; with co-workers; with his team; with direct boss; with managerial system and harmony between departments; between individual worker and the corporate leader; between people inside and those outside organizations. Given Chin's (2010) measure on organizational harmony seems to be especially appropriate for assessing the level of harmony in Chinese organizations, this indigenous model is employed as the cultural variable to test our hypotheses in this paper.

Integrating the foregoing discussions, on the basis that ethical leadership acts on corporate culture, the first hypothesis that the degree of ethical leadership an employee rates is likely to influence the level of harmony an employee perceives within a Chinese organization is shown as follows.

Hypothesis 1: The degree of ethical leadership an employee rates is positively related to the level of harmony an employee perceives in the Chinese workplace.

\subsection{Voice Behaviors}

In reviewing the literature on employee positive behavior, research on voice behavior has grown and evolved greatly during the past decades. It is believed that "voice" can be used as an effective means for workers to become more involved in their workplace and to help their organizations to innovate because it is primarily motivated by individual desire to express dissatisfaction as well as suggest improvements (Liang et al., 2012; Venkataramani \& Tangirala, 2010; Van Dyne, Ang, \& Botero, 2003).

In the literature, voice behavior is often defined as a kind of intentional, speaking-up behavior by employees to deliver constructive opinions and ideas on work-related issues that facilitate organizations to achieve better effectiveness or avoid potential crises (Liang et al., 2012; Venkataramani \& Tangirala, 2010; Van Dyne et al., 2003). However, according to the definition provided by the United States Department of Labor, employee voice is a "worker's ability to access information on their rights in the workplace, their understanding of those rights, and their ability to exercise those rights without fear of discrimination or retaliation." Despite some differences, the importance of a work environment with ethics and psychological safety to motivate employees' voice behavior is highlighted and identified when comparing the two definitions. Indeed, unlike citizenship behavior that is discretionary but quite beneficial for organizations, voice appears to be a planned and inherently challenging given it attempts to change the status quo and thus may raise increased visibility as well as the risks of being misunderstood or misinterpreted, such as unsolicited interference and bossiness (Tepper, Duffy, Hoobler, \& Ensley, 2004). Due to the potential risks associated with voicing at workplace, it is plausible to assume that employees may be more willing to engage in voice behaviors such as expressing their dissent opinions and giving novel suggestions when working under an ethical leader.

Hypothesis 2: Ethical leadership is positively related to employee voice behavior in the Chinese workplace. 
As noted earlier, this research aims to address whether ethical leaders enhance followers' voice behavior via the mediating mechanism of cultural variables (i.e., employee-perceived harmony at workplace). On the premise that ethical leadership is positively and significantly associated with the level of harmony and employee voice behavior (see Hypotheses 1 and 2), it can be further expected that the mediation effect of harmony on the relationship between ethical leadership and employee voice behavior also exists.

Hypothesis 3: Organizational harmony mediates the positive relationship between ethical leadership and employee voice behavior in the Chinese workplace.

\section{Methods}

\subsection{Population and Sample}

Data were collected randomly by questionnaire surveys from the membership lists of human resources associations in three cities in Guangdong Province in China: Guangzhou, Dongguang and Qingyuan. The sample selection was constrained to full-time employees working in private firms in manufacturing sectors only, in order to enhance comparability and reduce extraneous sources of variation and measurement error (Batt \& Colvin, 2011). Each questionnaire was accompanied by a note that explained the objective of the survey and assured anonymity and confidentiality. 1,200 questionnaires were distributed via post or email to randomly chosen employees and 590 usable data were received in total, yielding a response rate of $49.0 \%$. Of the respondents, $40 \%$ of participants were male while $60 \%$ were female. $43 \%$ of participants had less than or equal to 5 -year working experience, $60 \%$ of participants were older than 25 years old, and $17 \%$ of participants held managerial positions. $70 \%$ of participants had only senior high school or lower diplomas.

\subsection{Measures}

Three types of scales were included in this current research. The translation and back-translation procedures were employed to translate all English items into Chinese. In light of Chen, Jiang and Riley's (2003) suggestion, all instruments were measured using a six-point Likert-type scales ( $1=$ strongly disagree to $6=$ extremely agree) to prevent response bias because Chinese people tend to choose the mid-point of the scale regardless their true feelings or attitudes.

Ethical Leadership. Referring to Brown et al.'s (2005) ethical leadership model, this research measured employee-rated ethical leadership by a nine-item scale (Cronbach's $\alpha=0.904)$. A sample item is "my leader conducts his/her personal life in an ethical manner".

Organizational Harmony. Referring to Chin's (2010; 2012) measurement on the Chinese notion of harmony at workplace, our scale for measuring the level of organizational harmony contains 32 items (Cronbach's $\alpha=0.940$ ): four items are for harmony of individual worker with himself $(\alpha=0.800)$, four for harmony of co-workers $(\alpha=0.844)$, four for harmony of individual worker with his team $(\alpha=0.920)$, four for harmony of employee with his direct supervisor $(\alpha=0.896)$, four for harmony of individual worker with the managerial system (Cronbach's $\alpha=0.894)$, four for harmony between departments $(\alpha=0.805)$, four for harmony between individual worker with the corporate leader $(\alpha=0.900)$, and four for harmony between people inside and outside organizations $(\alpha=0.870)$.

Employee voice. Referring to Liang et al.'s (2012) study, a scale consisting of three items was used to assess employee self-reported voice behavior (Cronbach's $\alpha=0.867$ ). A sample item is "I proactively develop and make suggestions for issues that may influence the unit".

Control variables. According to the previous research (Batt \& Colvin, 2011), several variables that may influence employees' attitude towards their organizations were considered as control variables in this paper. Four organizational variables were controlled for, those were: industrial type (labor intensive $=1$, technology and capital-intensive industries $=0)$, workforce size $(>300$ workers $=1,<=300$ workers $=0)$, firm age $(>10$ years $=1$, others $=0$ ) and whether the firm had at least a round of mass lay-offs in the last year (lay-offs $=1$, others $=0$ ). In terms of the demographic control variables, five variables were controlled for: age $(<=25$ years old $=1$, others $=0)$, gender $(\mathrm{male}=0$, female $=1$ ), education level (senior high school or lower $=1$, others $=0$ ), individual working experience $(<=5$ years $=1$, others $=0$ ), and whether an employee held a managerial position (management $=1$, other $=0$ ).

\subsection{Construct Validity and Common Method Variance}

As noted, Cronbach $\alpha$ for each construct in our study is above 0.80 , indicating adequate reliability. To ensure the construct validity, a confirmatory factor analysis (CFA) was employed to further examine the construct distinctiveness of the harmony model. As a result, fit indexes indicated a good fit $\left(\chi_{\mathrm{n}=590}^{2}=1496.54, \mathrm{df}=436\right.$, 
$\mathrm{p}<.001 ; \mathrm{RMSEA}=.064<.08 ; \mathrm{SRMR}=.055<.08 ; \mathrm{CFI}=.98>.90 ; \mathrm{NNFI}=.98>.90)$. The results of CFA supported the proposed eight-factor structure. Therefore, our measures demonstrated satisfactory validity.

Since information about the dependent and independent variables in our research come from the same respondents, the potential for common method variance (CMV) could not be ignored. In light of the statistical remedial approach recommended by Podsakoff, Mackenzie, Lee, and Podsakoff (2003), all perceptual items were entered into an exploratory factor analysis. CMV will be a concern if a single factor emerges from the factor analysis, or one general factor accounts for the majority of the covariance among the variables (Podsakoff et al., 2003). The factor analysis of all measurement items resulted in a ten-factor construct accounting for $72.897 \%$ of the total variance, in which the largest factor only explained $17.663 \%$ of the total variance. Because a single factor did not emerge and the highest factor did not account for most of the variance, according to Podsakoff et al. (2003), CMV is unlikely to be a concern in terms of our data.

\section{Results}

According to MacKinnon, Lockwood, Hoffman, West, and Sheets' (2002) suggestion, the most commonly cited approach for testing mediation in human resource management and relevant fields is the hierarchical multiple regression (HMR) procedure recommended by Baron and Kenny (1986). Hence, it appeared be suitable to use HMR to examine our assumed mediation model as well. For the sake of methodological rigor, a path model-based approach was conducted (i.e., the Sobel test) (Sobel, 1988; MacKinnon et al., 2002) to further confirm the results. More specifically, the regression analysis was adopted to test our Hypotheses 1 and 2 first. Then the HMR was employed to examine our Hypothesis 3. In all regression models, all control variables noted above were included.

Table 1 shows the descriptive statistics including mean, standard deviations and correlations for all perceptual variables. Ethical leadership had positive relationships with all eight dimensions of Chinese harmony $(\mathrm{p}<.01)$ as well as with voice behavior $(\mathrm{p}<.01)$. The correlation coefficients between employee voice behavior and the eight dimensions of Chinese harmony were also significant $(\mathrm{p}<.01)$.

Table 1. Means, standard deviations, and correlations ( $\mathrm{N}=590)$

\begin{tabular}{|c|c|c|c|c|c|c|c|c|c|c|c|}
\hline & Mean & s.d. & EL & $\mathrm{AC}$ & F1 & F2 & F3 & F4 & F5 & F6 & F7 \\
\hline Ethical leadership (EL) & 4.0864 & .99421 & 1 & & & & & & & & \\
\hline Voice behavior & 3.9029 & 1.14649 & $.463 * *$ & 1 & & & & & & & \\
\hline F1 Self-harmony & 4.3799 & 1.05804 & $.237 * *$ & $.210^{* *}$ & 1 & & & & & & \\
\hline F2 Harmony of coworkers & 4.3456 & .98432 & $.402 * *$ & $.253 * *$ & $.546^{* *}$ & 1 & & & & & \\
\hline F3 Harmony with his team & 4.1852 & 1.10608 & $.547 * *$ & $.395 * *$ & $.418^{* *}$ & $.559 * *$ & 1 & & & & \\
\hline $\begin{array}{l}\text { F4 Harmony with direct } \\
\text { supervisor }\end{array}$ & 4.1707 & 1.13550 & $.609 * *$ & $.377 * *$ & $.354 * *$ & $.511^{* *}$ & $.591^{* *}$ & 1 & & & \\
\hline $\begin{array}{l}\text { F5 Harmony with managerial } \\
\text { systems }\end{array}$ & 3.8544 & 1.12184 & $.418^{* *}$ & $.409 * *$ & $.385^{* *}$ & $.432 * *$ & $.546^{* *}$ & $.575^{* *}$ & 1 & & \\
\hline $\begin{array}{l}\text { F6 Harmony between } \\
\text { departments }\end{array}$ & 3.98529 & .989047 & $.481 * *$ & $.374 * *$ & $.403 * *$ & $.456^{* *}$ & $.605^{* *}$ & $.601 * *$ & $.611^{* *}$ & 1 & \\
\hline $\begin{array}{l}\text { F7 Harmony with the highest } \\
\text { leader }\end{array}$ & 4.0780 & 1.12133 & $.585 * *$ & $.411^{* *}$ & $.260 * *$ & $.391 * *$ & $.533 * *$ & $.644 * *$ & $.563 * *$ & $.578^{* *}$ & 1 \\
\hline $\begin{array}{l}\text { F8 Harmony between insiders } \\
\text { and outsiders }\end{array}$ & 4.3772 & .92818 & $.462 * *$ & $.367 * *$ & $.462 * *$ & $.517 * *$ & $.576^{* *}$ & $.533 * *$ & $.510^{* *}$ & $.552 * *$ & $.488 * *$ \\
\hline
\end{tabular}

Table 2 provides the regression results between ethical leadership and the eight dimensions of Chinese harmony, respectively. In line with our expectations, the results indicate that higher level of ethical leadership rated by an employee significantly increases an employee's perception of harmony level within an organization. Model 1 to Model 8 show that ethical leadership are positively related to harmony of individual worker with himself $(\beta=0.260, \mathrm{p}<.001)$, harmony of coworkers $(\beta=0.406, \mathrm{p}<.001)$, harmony of individual worker with his team $(\beta=0.563, \mathrm{p}<.001)$, harmony of individual worker with his supervisor $(\beta=0.625, \mathrm{p}<.001)$, harmony of individual 
worker with the managerial system $(\beta=0.436, p<.001)$, harmony between departments $(\beta=0.513, p<.001)$, harmony between individual worker and the corporate leader $(\beta=0.596, p<.001)$, and harmony between people inside and outside organizations $(\beta=0.455, \mathrm{p}<.001)$. Our hypothesis 1 therefore is fully supported.

Table 2. Results of regression analysis between EL and Harmony

\begin{tabular}{|c|c|c|c|c|c|c|c|c|}
\hline & Model 1 & Model 2 & Model 3 & Model 4 & Model 5 & Model 6 & Model 7 & Model 8 \\
\hline & $\begin{array}{l}\text { Harmoy } \\
\text { (F1) }\end{array}$ & $\begin{array}{l}\text { Harmony } \\
\text { (F2) }\end{array}$ & $\begin{array}{l}\text { Harmony } \\
\text { (F3) }\end{array}$ & $\begin{array}{l}\text { Harmony } \\
\text { (F4) }\end{array}$ & $\begin{array}{l}\text { Harmony } \\
\text { (F5) }\end{array}$ & $\begin{array}{l}\text { Harmony } \\
\text { (F6) }\end{array}$ & $\begin{array}{l}\text { Harmony } \\
\text { (F7) }\end{array}$ & $\begin{array}{l}\text { Harmony } \\
\text { (F8) }\end{array}$ \\
\hline \multicolumn{9}{|c|}{ Independent variables } \\
\hline EL & $\begin{array}{c}0.274 * * * \\
(0.043)\end{array}$ & $\begin{array}{c}0.394 * * * \\
(0.037)\end{array}$ & $\begin{array}{c}0.618 * * * \\
(0.038)\end{array}$ & $\begin{array}{c}0.706^{* * * *} \\
(0.037)\end{array}$ & $\begin{array}{c}0.483 * * * \\
(0.042)\end{array}$ & $\begin{array}{c}0.628^{* * * *} \\
(0.175)\end{array}$ & $\begin{array}{c}0.667 * * * \\
(0.038)\end{array}$ & $\begin{array}{c}0.419 * * * \\
(0.034)\end{array}$ \\
\hline \multicolumn{9}{|l|}{ Control variables } \\
\hline $\begin{array}{l}\text { Gender } \\
(\text { Female }=1) \text {, }\end{array}$ & $\begin{array}{c}0.069 \\
(0.092)\end{array}$ & $\begin{array}{c}0.078 \\
(0.079)\end{array}$ & $\begin{array}{l}-0.069 \\
(0.081)\end{array}$ & $\begin{array}{l}0.146 \dagger \\
(0.079)\end{array}$ & $\begin{array}{c}0.039 \\
(0.090)\end{array}$ & $\begin{array}{c}0.123 \\
(0.075)\end{array}$ & $\begin{array}{c}0.063 \\
(0.081)\end{array}$ & $\begin{array}{c}0.041 \\
(0.072)\end{array}$ \\
\hline $\begin{array}{l}\text { Working yrs } \\
(<=5 \text { years }=1)\end{array}$ & $\begin{array}{c}0.041 \\
(0.170)\end{array}$ & $\begin{array}{c}0.221 \\
(0.147)\end{array}$ & $\begin{array}{c}0.022 \\
(0.150)\end{array}$ & $\begin{array}{c}0.094 \\
(0.147)\end{array}$ & $\begin{array}{l}-0.245 \\
(0.166)\end{array}$ & $\begin{array}{l}-0.040 \\
(0.139)\end{array}$ & $\begin{array}{c}0.011 \\
(0.150)\end{array}$ & $\begin{array}{c}0.156 \\
(0.134)\end{array}$ \\
\hline $\begin{array}{l}\text { Age } \\
(<=25 \text { yrs old }=1)\end{array}$ & $\begin{array}{l}-0.148 \\
(0.106)\end{array}$ & $\begin{array}{c}0.034 \\
(0.091)\end{array}$ & $\begin{array}{l}-0.104 \\
(0.093)\end{array}$ & $\begin{array}{l}-0.029 \\
(0.091)\end{array}$ & $\begin{array}{c}0.030 \\
(0.103)\end{array}$ & $\begin{array}{c}0.096 \\
(0.086)\end{array}$ & $\begin{array}{l}-0.081 \\
(0.093)\end{array}$ & $\begin{array}{c}0.020 \\
(0.083)\end{array}$ \\
\hline $\begin{array}{l}\text { Education } \\
(<=\text { senior high }=1)\end{array}$ & $\begin{array}{c}0.095 \\
(0.093)\end{array}$ & $\begin{array}{l}-0.077 \\
(0.080)\end{array}$ & $\begin{array}{l}-0.071 \\
(0.082)\end{array}$ & $\begin{array}{c}0.014 \\
(0.081)\end{array}$ & $\begin{array}{c}0.067 \\
(0.091)\end{array}$ & $\begin{array}{c}.0 .096 \\
(0.076)\end{array}$ & $\begin{array}{l}-0.054 \\
(0.082)\end{array}$ & $\begin{array}{c}0.223 * * \\
(0.073)\end{array}$ \\
\hline Job position & $\begin{array}{c}0.344 \\
(0.262)\end{array}$ & $\begin{array}{l}0.445^{*} \\
(0.225)\end{array}$ & $\begin{array}{c}0.195 \\
(0.230)\end{array}$ & $0.383 \dagger$ & 0.015 & $0.379 \dagger$ & -0.115 & 0.141 \\
\hline $\begin{array}{l}\text { (Management=1) } \\
\text { Recent lay-offs }\end{array}$ & $\begin{array}{l}(0.262) \\
-0.344\end{array}$ & $\begin{array}{l}(0.225) \\
-0.404 \dagger\end{array}$ & $\begin{array}{l}(0.230) \\
-0.262\end{array}$ & $\begin{array}{l}(0.226) \\
-0.378\end{array}$ & $\begin{array}{c}(0.255) \\
0.013\end{array}$ & $\begin{array}{l}(0.213) \\
-0.169\end{array}$ & $\begin{array}{c}(0.231) \\
0.064\end{array}$ & -0.260 \\
\hline$($ Lay-offs $=1)$ & $(0.279)$ & $(0.241)$ & $(0.246)$ & $(0.241)$ & $(0.272)$ & $(0.228)$ & $(0.246)$ & $(0.219)$ \\
\hline Industrial type & 0.156 & 0.187 & 0.190 & 0.164 & $0.453 * *$ & 0.175 & 0.204 & $0.357^{*}$ \\
\hline (Labor intensive $=1$ ) & $(0.194)$ & $(0.167)$ & $(0.171)$ & $(0.167)$ & $(0.189)$ & $(0.158)$ & $(0.171)$ & $(0.152)$ \\
\hline Firm age & -0.148 & $-0.307 \dagger$ & $-0.270 \dagger$ & -0.090 & 0.290 & 0.045 & -0.092 & -0.216 \\
\hline$(>10 \mathrm{yrs}=1)$ & $(0.184)$ & $(0.158)$ & $(0.162)$ & $(0.159)$ & $(0.179)$ & $(0.150)$ & $(0.162)$ & $(0.144)$ \\
\hline Firm size & 0.063 & 0.069 & 0.039 & $0.135 \dagger$ & 0.125 & $0.198 * *$ & 0.038 & 0.072 \\
\hline$(>300$ people $=1)$ & $(0.094)$ & $(0.081)$ & $(0.083)$ & $(0.081)$ & $(0.091)$ & $(0.077)$ & $(0.083)$ & $(0.074)$ \\
\hline Constant & $\begin{array}{l}1.025 * * * \\
(0254)\end{array}$ & $\begin{array}{c}2.683 * * * \\
(0.184)\end{array}$ & $\begin{array}{c}1.835^{* * *} \\
(0188)\end{array}$ & $1.119 * * *$ & $\begin{array}{c}1.718 * * * \\
(0209)\end{array}$ & $1.628 * * *$ & $\begin{array}{c}1.379 * * * \\
(0.189)\end{array}$ & $\begin{array}{c}2.424 * * * \\
(0.168)\end{array}$ \\
\hline $\mathrm{R}^{2}$ & $\begin{array}{c}(0.254) \\
0.077\end{array}$ & $\begin{array}{c}(0.184) \\
0.189\end{array}$ & $\begin{array}{c}(0.188) \\
0.341\end{array}$ & $\begin{array}{c}(0.185) \\
0.399\end{array}$ & $\begin{array}{c}(0.209) \\
0.206\end{array}$ & $\begin{array}{c}(0.175) \\
0.292\end{array}$ & $\begin{array}{c}(0.189) \\
0.362\end{array}$ & $\begin{array}{c}(0.168) \\
0.253\end{array}$ \\
\hline F & $4.762 * * *$ & $13.241^{* * *}$ & $29.299 * * *$ & $37.585^{* * *}$ & $14.687^{* * *}$ & $23.422 * * *$ & $32.140 * * *$ & $19.172 * * *$ \\
\hline
\end{tabular}

$\mathrm{N}=592, \dagger p<0.10,{ }^{*} p<0.05,{ }^{* *} p<0.01, * * * p<0.001$ Significance levels based on two-tailed tests.

Unstandardized regression coefficients are reported; robust standard errors are given in parentheses.

To examine the mediation effect, we referred to Zhou, Banes, and Lu's (2010) suggestion to reduce parameters by averaging the eight sub constructs of the model of Chinese harmony to form a composite score indicator representing the level of harmony. Table 4 summarizes the regression results including Hypothesis 2 and Hypothesis 3. As shown in Model 10 in Table 3, ethical leadership was regressed with voice behavior $(\beta=0.505$, $\mathrm{p}<.001$ ). Accordingly, Hypothesis 2 is supported as well.

Following the HMR approach, in Model 10, ethical leadership was firstly regressed on voice behavior $(\beta=0.505$, $\mathrm{p}<.001)$ and then ethical leadership was regressed with the level of harmony in Model $11(\beta=0.653, p<.001)$. The foregoing results that showed significant relationships between these variables were proved to fit the basic requirements of a mediation model.

Next, both ethical leadership and the level of harmony were entered as independent variables to test the mediating effect of harmony in Model 12. Compared with Model 10, Model 12 shows that the relationship between ethical leadership and voice behavior was still significant $(\beta=0.329, p<.001)$ but the magnitude of the coefficient decreased ( $\beta$ from 0.505 to 0.329 ). This finding appears to indicate the existence of the mediating effect of the level of harmony. To further examine it, the Sobel test was performed (Sobel, 1988; MacKinnon et al., 2002) $(\mathrm{Z}=4.081>3.29, \mathrm{p}<.001)$. The results confirm that the level of harmony partially mediates the relationship between ethical leadership and employee behavior. Hypothesis 3 is supported. 
Table 3. Results of regression analysis on mediating effect

\begin{tabular}{|c|c|c|c|c|}
\hline & Model 9 & Model 10 & Model 11 & Model 12 \\
\hline & $\begin{array}{l}\text { Voice Behavior } \\
\text { (H2) }\end{array}$ & Voice Behavior & Harmony & $\begin{array}{c}\text { Mediation Effect } \\
\text { (H3) }\end{array}$ \\
\hline \multicolumn{5}{|c|}{ Independent variables } \\
\hline Level of harmony & $\begin{array}{c}0.697 * * * \\
(0.053)\end{array}$ & & & $\begin{array}{c}0.392 * * * \\
(0.066)\end{array}$ \\
\hline Ethical leadership & & $\begin{array}{c}0.573 * * * \\
(0.041)\end{array}$ & $\begin{array}{c}0.508 * * * \\
(0.025)\end{array}$ & $\begin{array}{c}0.373 * * * \\
(0.052)\end{array}$ \\
\hline $\begin{array}{l}\text { Control variables } \\
\text { Gender } \\
(\text { Female }=1) \text {, }\end{array}$ & $\begin{array}{l}-0.082 \\
(0.088)\end{array}$ & $\begin{array}{l}-0.004 \\
(0.087)\end{array}$ & $\begin{array}{c}0.061 \\
(0.054)\end{array}$ & $\begin{array}{l}-0.028 \\
(0.085)\end{array}$ \\
\hline $\begin{array}{l}\text { Working experience } \\
(<=5 \text { years }=1)\end{array}$ & $\begin{array}{l}-0.246 \\
(0.164)\end{array}$ & $\begin{array}{l}-0.260 \\
(0.161)\end{array}$ & $\begin{array}{c}0.032 \\
(0.100)\end{array}$ & $\begin{array}{l}-0.273 \dagger \\
(0.157)\end{array}$ \\
\hline Age & -0.129 & $-0.183 \dagger$ & -0.023 & $-0.174 \dagger$ \\
\hline$(<=25$ yrs old $=1)$ & $(0.101)$ & $(0.100)$ & $(0.062)$ & $(0.097)$ \\
\hline Education level & 0.134 & $0.163 \dagger$ & 0.037 & $0.148 \dagger$ \\
\hline$(<=$ senior high $=1)$ & $(0.090)$ & $(0.088)$ & $(0.055)$ & $(0.086)$ \\
\hline Job position & $0.416 \dagger$ & $0.601^{*}$ & 0.223 & 0.513 \\
\hline (Management=1) & $(0.252)$ & $(0.248)$ & $(0.154)$ & $(0.241)$ \\
\hline Recent lay-offs & -0.197 & -0.357 & -0.218 & -0.271 \\
\hline$($ Lay-offs $=1)$ & $(0.269)$ & $(0.265)$ & $(0.164)$ & $(0.258)$ \\
\hline Industrial type & -0.114 & 0.002 & $0.236^{*}$ & -0.090 \\
\hline$($ Labor intensive $=1)$ & $(0.187)$ & $(0.184)$ & $(0.114)$ & $(0.179)$ \\
\hline Firm age & $0.534 * *$ & $0.530^{* *}$ & -0.098 & $0.568^{* *}$ \\
\hline$(>10$ yrs $=1)$ & $(0.177)$ & $(0.174)$ & $(0.108)$ & $(0.169)$ \\
\hline Firm size & $-0.151 \dagger$ & -0.067 & $0.092 \dagger$ & -0.103 \\
\hline$(>300$ people $=1)$ & $(0.090)$ & $(0.089)$ & $(0.055)$ & $(0.087)$ \\
\hline \multirow[t]{2}{*}{ Constant } & $0.939 * * *$ & $1.418^{* * *}$ & $2.005 * * *$ & $0.632 * * *$ \\
\hline & $(0.244)$ & $(0.203)$ & $(0.126)$ & $(0.237)$ \\
\hline $\mathrm{R}^{2}$ & 0.263 & 0.282 & 0.432 & 0.324 \\
\hline $\mathrm{F}$ & $20.203 * * *$ & $22.290 * * *$ & $43.155^{* * *}$ & $24.712 * * *$ \\
\hline
\end{tabular}

\section{Discussion}

The empirical findings in this study lend support to our hypotheses. First, the results suggest that employee-rated ethical leadership is significantly related to employee-perceived harmony in eight dimensions within a Chinese organization. Second, the positive relationship between ethical leadership and employee voice behavior is observable as well. Third, findings are consistent with the predicted mediation model that the level of harmony positively mediates the relationship between ethical leadership and employee voice behavior.

\subsection{Contributions and Implications}

In sum, this research yields three main contributions. First, given research on ethical leadership is still in its early stages of development (Mayer et al., 2012; Hannah et al., 2011; Ardichvili \& Jondle, 2009), a key implication of this study is to shed light on the critical role of ethical leadership in management practices in the complex yet dynamic Chinese context. It brings new insights into the leadership literature, examining that ethical leadership may motivate employee voice behavior via increasing organizational harmony in China. More specifically, the interrelationship between ethical leadership and a specific cultural context indeed significantly affects employee behavior at work.

Second, this research advances the current HRM literature, seeing that it incorporates the unique cultural characteristic "harmony" in China into the mechanism between employee-rated ethical leadership and voice behavior. Given the existing Western theories that currently dominate the HRM literature may not be always adequate to meet the need of workers in China due to the cultural differences, this study, therefore, is in response to the recent appeal for developing context-sensitive indigenous theories and analyzing country-specific phenomena (Tusi, Nifadkar, \& Ou, 2007; Whetten, 2009).

Third, in terms of practical implications, this paper especially enables non-Chinese entrepreneurs to gain a better understanding of the positive influence of ethical leadership on the level of harmony in Chinese organizations. Our results suggest that facing highly uncertain business environment in China, managers could put more effort into displaying ethical behaviors to develop a harmonious leader-follower relationship and through which to 
encourage employees to speak up for promoting organizational health. In addition, our findings implicitly indicate that if the level of harmony is low, the efficacy of ethical leadership may not be completely translated into an employee's exhibition of voice behavior in China.

\subsection{Limitation and Future Research}

It is acknowledged that this current research is subject to limitations. For instance, a non-experimental research design was used to examine the mediation effects and therefore, the causality of the findings is relatively implied. Future research should use alternative and more rigorous methods. Although the data were collected from several cities, our samples may not be representative of the huge working population in China. Future research should include more diversified samples to generate more fruitful results. Moreover, for the sake of parsimony, only the self-reported and individual-level data were used in this paper. Future research should also include group-level, firm-level and multi-source data into considerations that may help to further explain how the stakeholders of a firm react to ethical leadership.

\subsection{Conclusion}

In conclusion, this present research examining that ethical leadership serves to bolster organizational harmony in Chinese firms elucidates that different contexts, such as national cultures, significantly relates to the processing and efficacy of ethical leadership. Given our proposed framework is not context neural, this paper indeed to a certain extent unveils the "black box" of the profound interplay and connection between ethical leadership and a specific cultural context.

Scholars have been encouraged to discover in depth the impact of Chinese wisdom on HRM in order to move toward a true sense of melting-pot integrating Eastern cultural traits into the essential notions of Western theories. This paper-which uncovers a previously unexplored mechanism about how ethical leadership enhances employee voice behavior through increasing organizational harmony in China-provides a novel and insightful example in regard to tailoring Western HRM to the Chinese context.

\section{References}

Ardichvili, A., \& Jondle, D. (2009). Ethical Business Cultures: A Literature Review and Implications for HRD. Human Resource Development Review, 8(2), 223-244. http://dx.doi.org/10.1177/1534484309334098

Ardichvili, A., Jondle, D., Kowske, B., Cornachione, E., Li, J., \& Thakadipuram, T. (2011). Ethical Cultures in Large Business Organizations in Brazil, Russia, India, and China. Journal of Business ethics.

Ardichvili, A., Mitchell, J., \& Jondle, D. (2009). Characteristics of ethical business cultures. Journal of Business Ethics, 85, 445-451. http://dx.doi.org/10.1007/s10551-008-9782-4

Avolio, B. J., \& Gardner, W. L. (2005). Authentic leadership development: Getting to the root of positive forms of leadership. The Leadership Quarterly, 16, 315-338. http://dx.doi.org/10.1016/j.leaqua.2005.03.001

Bandura, A. (1986). Social foundations of thought and action: A social cognitive theory. Englewood Cliff, N. J.: Prentice-Hall.

Baron, R. M., \& Kenny, D. A. (1986). The moderator-mediator variable distinction in social psychological research: Conceptual, strategic, and statistical considerations. Journal of Personality and Social Psychology, 51, 1173-1182. http://dx.doi.org/10.1037/0022-3514.51.6.1173

Batt, R., \& Colvin, A. J. S. (2011). An employment systems approach to turnover: Human resource practices, quits, dismissals, and performance. Academy of management Journal, 54(4), 695-717. http://dx.doi.org/10.5465/AMJ.2011.64869448

Brown, M. E., \& Trevino, L. K. (2006). Ethical leadership: A review and future directions. Leadership Quarterly, 17, 595-616. http://dx.doi.org/10.1016/j.leaqua.2006.10.004

Brown, M. E., Trevino, L. K., \& Harrison, D. A. (2005). Ethical leadership: A social learning perspective for construct development and testing. Organizational Behavior and Human Decision Processes, 97, 117-134. http://dx.doi.org/10.1016/j.obhdp.2005.03.002

Butcher, W. (1997). The need for ethical leadership. Executive Speeches, 11(5), 83-86.

Chen, M., \& Miller, D. (2011). The relational perspective as a business mindset: managerial implications for East and West. Academy of Management Perspectives, 25(3), 6-18. http://dx.doi.org/10.5465/AMP.2011.63886526

Chen, S. (2010). The role of ethical leadership versus institutional constraints: A simulation study of financial 
misreporting by CEOs. Journal of Business Ethics. http://dx.doi.org/10.1007/s10551-010-0625-8

Cheng, B., Jiang, D., \& Riley, J. H. (2003). Organizational commitment, supervisory commitment and employee outcomes in the Chinese context: Proximal hypothesis or global hypothesis? Journal of Organizational Behavior, 24, 313-334. http://dx.doi.org/10.1002/job.190

Cheng, C. (2006). Toward constructing a dialectics of harmonization: Harmony and conflict in Chinese philosophy. Journal of Chinese Philosophy, 33(1), 25-59. http://dx.doi.org/10.1111/j.1540-6253.2006.00389.x

Chin, T. (2010). An empirical study on harmonious organizations. Journal of Sun Yat-sen University, 50(3), $164-174$.

Chin, T. (2012). Harmony in Chinese organizations: From the perspective of national culture. Journal of Strategy and Decision-making, 3(5), 42-50.

Chin, T. (2013). An exploratory study on upgrading by FDI OEMs in China. International Business Research, 6(1), 199-210.

Fung, Y. L. (1948). In Derk Bodde (Ed.), A short history of Chinese Philosophy. New York: Free Press.

Han, Y., \& Altman, Y. (2010). Confucian moral roots of citizenship behaviour in China. Asia-Pacific Journal of Business, 2(1), 35-52.

Hannah, S. T., Avolio, B. J., \& May, D. R. (2011). Moral Maturation and Moral Conation: A Capacity Approach to Explaining Moral Thought and Action. Academy of management Review, 36(4), 663-685.

Hofstede, G., Hofstede, G. J., \& Minkov, M. (2010). Cultures and organizations. U. S.: McGraw-Hill.

Kirkman, B. L., Chen, G., Farh, J. L., Chen, Z. X., \& Lowe, K. B. (2009). Individual power reactions to transformational leaders: A cross-level, cross-cultural examination. Academy of Management Journal, 52(4), 744-764. http://dx.doi.org/10.5465/AMJ.2009.43669971

Lai, K. L. (2008). An Introduction to Chinese Philosophy. UK: Cambridge University Press. http://dx.doi.org/10.1017/CBO9780511800832

Leung, K., Brew, F. P., Zhang, Z., \& Zhang, Y. (2011). Harmony and conflict: A cross-cultural investigation in China and Australia. Journal of Cross-cultural Psychology, 42(5), 795-816. http://dx.doi.org/10.1177/0022022110363474

Luo, Y., \& Rui, H. (2009). An ambidexterity perspective toward multinational enterprises from emerging $\begin{array}{llll}\text { economies. Academy of } & \text { Management }\end{array}$ http://dx.doi.org/10.5465/AMP.2009.45590140

Mackinnon, D. P., Lockwood, C. M., Hoffman, J. M., West, S. G., \& Sheets, V. (2002). A comparison of methods to test mediation and other intervening variable effects. Psychological Methods, 7, 83-104. http://dx.doi.org/10.1037/1082-989X.7.1.83

Mayer, D. M., Aquino, K., Greenbaum, R. L., \& Kuenzi, M. (2012). Who displays ethical leadership, and why does it matter? An examination of antecedents and consequences of ethical leadership. Academy of Management Journal, 55(1), 151-171. http://dx.doi.org/10.5465/amj.2008.0276

Podsakoff, P. M., Mackenzie, S. B., Lee, J. Y., \& Podsakoff, N. P. (2003). Common method bias in behavioral research: A critical review of the literature and recommended remedies. Journal of Applied Psychology, 88, 879-903. http://dx.doi.org/10.1037/0021-9010.88.5.879

Schminke, M., Arnaud, A., \& Kuenzi, M. (2007). The power of ethical work climates. Organizational Dynamics, 36, 171-183. http://dx.doi.org/10.1016/j.orgdyn.2007.03.005

Sobel, M. E. (1988). Direct and indirect effects in linear structural equation models. In J. S. Long (Ed.), Common Problems/Proper Solutions (pp. 46-64). CA: Sage.

Tepper, B. J., Duffy, M. K., Hoobler, J., \& Ensley, M. D. (2004). Moderators of the relationships between co-workers' organizational citizenship behavior and fellow employees' attitude. Journal of Applied Psychology, 89, 455-465. http://dx.doi.org/10.1037/0021-9010.89.3.455

Tjosvold, D., Wu, P., \& Chen, Y. F. (2010). The effects of collectivistic and individualistic values on conflict and decision making: An experiment in China. Journal of Applied Social Psychology, 49(11), 2904-2926. http://dx.doi.org/10.1111/j.1559-1816.2010.00686.x 
Tusi, A. S., Nifadkar, S. S., \& Ou, A. Y. (2007). Cross National, cross-cultural organizational behavior research: Advances, gaps, and recommendations. Journal of Management, 33, 426-478. http://dx.doi.org/10.1177/0149206307300818

Van Dyne, L., Ang, S., Botero, I. C. (2003). Conceptualizing employee silence and employee voice as multidimensional constructs. Journal of Management Studies, 40, 1359-1392. http://dx.doi.org/10.1111/1467-6486.00384

Venkataramani, V., \& Tangirala, S. (2010). When and why do central employees speak up? An examination of mediating and moderating variables. Journal of Applied Psychology, 95, 582-591. http://dx.doi.org/10.1037/a0018315

Walumbwa, F. O., \& Schaubroeck, J. (2009). Leader personality traits and employee voice behavior: Mediating roles of ethical leadership and work group psychological safety. Journal of Applied Psychology, 94, 1275-1286. http://dx.doi.org/10.1037/a0015848

Whetten, D. A. (2009). An Examination of the Interface between Context and Theory Applied to the Study of Chinese Organizations. Management and Organization Review, 5(1), $29-55$. http://dx.doi.org/10.1111/j.1740-8784.2008.00132.x

Zhou, B. (2004). Zhou Yi Tong Yi. Beijing: Kunlun Publishing.

Zhou, L., Banes, B. R., \& Lu, Y. (2010). Entrepreneurial proclivity, capability upgrading and performance advantage of newness among international new ventures. Journal of International Business Studies, 41, 882-905. http://dx.doi.org/10.1057/jibs.2009.87

Zhu, W. (2008). The effect of leadership on follower moral identity: The mediating role of psychological empowerment. Leadership Review, 8, 62-73.

\section{Copyrights}

Copyright for this article is retained by the author(s), with first publication rights granted to the journal.

This is an open-access article distributed under the terms and conditions of the Creative Commons Attribution license (http://creativecommons.org/licenses/by/3.0/). 